\title{
Desafios para a rede nacional de laboratórios de vigilância sanitária: o caso dos medicamentos manipulados
}

\author{
Challenges to the national network of sanitary surveillance \\ laboratories: the case of manipulated drugs
}

Ana Célia Pessoa da Silva ${ }^{1}$

Catia Veronica dos Santos Oliveira ${ }^{1}$

M aria Virginia Silva Caval heiro ${ }^{2}$

M aria do Carmo de Castro M iranda ${ }^{2}$

${ }^{1}$ Departamento de Administração e Planejamento em Saúde, Escola Nacional deSaúde Pública Sergio Arouca, Fundação Oswaldo Cruz. Av. Brasil 4.036/906, M anguinhos. 21040-361 Rio deJaneiro RJ. anacelia@ensp.fiocruz.br ${ }^{2}$ Instituto deQuímica, Instituto Nacional de ControledeQualidadeem Saúde, Fundação O swaldo Cruz.
Abstract From the research on the "Status of Pharmacy Formulated M edicines (PFM) in health surveillance laboratories (HSL)" as result of an agreement between Ensp and Anvisa, we present and question issues that may contribute for reflections about the $\mathrm{N}$ ational N etwork of HSL organization in confronting analytical demands, having PFM s as discussion organizers. The Public Laboratories (PL) that evaluated PFM s from 2000 to 2005 wereidentified; its analysts and samples were scanned, and three laboratories were selected to be visited. Sample processing was analyzed from its entry till the final report'sissuance. Samples study allowed identifying: applicants and sample's documents; HSL executors and how they receive, process and reply the analysis requests demands. Applicants are judiciary (20\%) and the health surveillance (HS) (74\%). Baseless claims represent $25 \%$. Seven HSL analyzed PFM s. $45 \%$ of thesamples previously passed by $15 \mathrm{PL}$; HR were insufficient to meet the claims' analytical complexity; little institutional culture in dealing with samples of PFM and HS; $31 \%$ of samples have no conclusion; $40 \%$ of the satisfactory reports and $23 \%$ of the unsatisfactory have not conducted adequate tests to answer the demand's reasons. In conclusion, H SLs must evaluate their working process. Key words $\mathrm{H}$ ealth surveillance, Laboratory evaluation, Pharmacy formulated medicines
Resumo A partir da pesquisa "Situação dos me dicamentos manipulados (M M s) nos laboratórios de vigilância sanitária (LVS)", produto do convênio Ensp/Anvisa, apresentam-seeproblematizamse elementos que possam contribuir para a refle xão sobrea estruturação da RedeN acional de LVS no enfrentamento de demandas analíticas, usando os M M s como organizadores da discussão. Identificaram-se os laboratórios públicos (LP) que avaliaram M M s no período de 2000 a 2005, perscrutaram-se seus analistas e as amostras e escolheram-se três laboratórios para visita. Analisou-seo processamento da amostra desde sua entrada atéa emissão do laudo. 0 estudo das amostras de M M s possibilitou identificar: os requerentes e a documentação da amostra; os LVS executores e como recebem, processam e respondem à demanda das solicitações de análises. O s requerentes são o Judiciário (20\%) ea Visa (74\%). Demandas infundadas somam $25 \%$. Sete LVS analisaram M M s. $45 \%$ das amostras passaram antes por $15 \mathrm{LP}$; RH insuficiente para a complexidade analítica das denúncias; pouca cultura institucional em lidar com amostras deM M seda Visa; $31 \%$ dasamostras sem conclusão. $40 \%$ dos laudos satisfatórios e $23 \%$ dos insatisfatórios não realizaram ensaios adequados à resposta dos motivos da demanda. Os LVS precisam avaliar seu processo de trabalho.

Palavras-chave Vigilância sanitária, Avaliação laboratorial, M edicamentos manipulados 
Introdução

A humanidade experimentou a dor ea delícia do uso de tecnologias. Aprendeu que toda e qualquer uma precisa ser avaliada quanto aos riscos e benefícios antes de sua disseminação no mercado. Um dos segmentos que mais contribuíram com esta necessidade de prudência foram os medicamentos, sendo hoje um dos mais regulamentados do mundo. Daí a função estatal deformular políticas ecriar instituições públicas capazes de definir e monitorar sua oferta terapêutica. É o Estado determinando os atributos imprescindíveis à "qualidade sanitária do medicamento" (QSM), entendida como binômio indissociável desegurança e eficácia, eoscritérios indispensáveis para sua demonstração, assim como todos os parâmetros que possam comprometê-la durante sua vida útil, antes de sua liberação para circulação e uso na sociedade ${ }^{1-4}$.

No Brasil, o Estado criou um corpo normativo e institucional para avaliar a concessão de registro e fiscalizar produção, transporte, prescrição, comercialização e uso de medicamentos no país há, pelo menos, trinta anos ${ }^{1,2}$. Esse arcabouço legal continua em vigor e adquiriu rele vância a partir da promulgação da Constituição Federal brasileira (CF) de 1988, quando determina que as ações e os serviços de saúde constituam um Sistema Ú nico de Saúde (SUS), regionalizado e hierarquizado. U ma de suas diretrizes é priorizar as atividades preventivas (art. 198, inciso II da CF), cujas atribuições, entre outras, são: controlar e fiscalizar procedimentos, produtos e substâncias de interesse para a saúde e executar ações de vigilância sanitária e epidemiológica (art. 200, incisos I ell, respectivamente, CF) ${ }^{5}$.

$\mathrm{Na}$ contramão do movimento de reforma sanitária brasileira e da história da regulamentação dos medicamentos, em que são crescentes as exigências de comprovação desegurança eeficácia de qualquer medicamento, inclusiveno Brasil ${ }^{1,2,4}$, surge o segmento das farmácias de manipulação. A própria Agência N acional de Vigilância Sanitária (Anvisa), em documento sobre as farmácias magistrais, afirma: Esse segmento passou por transformações nos últimos anos, com um crescimento importante, sem que houvesse definições claras pela sociedadee pelo Estado quanto ao seu papel. E prossegue: Em países onde já há regulamentação definindo o papel das farmácias de manipulação, estas têm papel complementar às indústrias

A lógica de as farmácias de manipulação suprirem apenas as lacunas da oferta terapêutica nacional, preparando medicamentos não disponíveis no mercado e necessários a um paciente específico, não refleteo cenário nacional ${ }^{7}$. Embora raros os casos de excepcionalidade, as farmácias de manipulação vêm se expandindo e vendendo a ideia de medicamento personalizado, nem sempre vinculado a uma prescrição ${ }^{7-9}$. Entre 1998 e 2002, o número de farmácias magistrais passou de 2.100 a $5.200^{10}$.

Fato é que, com 0 aumento à exposição do risco, não tardou a emergirem denúncias eapreensões de amostras envolvendo os medicamentos manipulados (M M s), associando-os a graves problemas sanitários: pessoas em coma, mortes associadas - inclusive na mesma família -, manifestação de intoxicação, além de municípios - buscando ampliar acesso barateando o custo - aderindo à produção artesanal em escala de bancada sem a devida observância das Boas Práticas de Fabricação $0^{8,9,11-13 .}$

Os eventos relatados eram evitáveis, uma vez que o maior problema decorre da impossibilidade técnica da manipulação de determinados fármacos. M esmo observados com rigor todos os critérios preconizados nos regulamentos, o risco é eminente. Corroborando esta afirmação, está a variação de conteúdo de princípio ativo que difereacentuadamente entreas diversas cápsulas de uma mesma formulação (partida), como de $40 \%$ a $180 \%$, ou $858 \%$ a $13.199 \%$ do declarado, conforme comprovado em análises no Instituto N acional deControledeQualidade (INCQS) da Fundação Oswaldo Cruz (Fiocruz) 9,11-13. A falta de uniformidade do conteúdo interfere diretamente na resposta terapêutica, acarretando falhas ou exacerbação do efeito adverso, inclusive da toxicidade.

A Anvisa reconhece: A garantia de segurança é um item fundamental. As exigências da vigilância sanitária obrigam as indústrias a realizar procedimentos de validação nas várias fases do processo produtivo. No caso da manipulação, os procedimentos para a garantia da qualidade são praticamente inviáveis [ ...]. Como consequência, o usuário final fica exposto ao risco dos er ros não detectados durante o processo de produção do medicamento. E acrescenta: Quando se trata de medicamentos dealta potência ebaixa dosagem, pequenas variações no processo de produção, incluindo a possibilidade de erros aleatórios imprevisíveis, podem levar a resultados catastróficos [...] uma partícula do tamanho de um grão de areia pode significar uma dose fatal ${ }^{6}$.

Sabe-se que a cinética de absorção depende criticamente dos excipientes e do modo de preparação, sendo desconhecida nos medicamentos magistrais. Os problemas que provocam falhas terapêuticas, acarretados por menor quantidade 
ou menor biodisponibilidade do princípio ativo em uma formulação individualizada, dificilmente serão rastreados e identificados no $M M$, sendo frequentemente atribuídos à própria patologia do paciente ${ }^{7,12}$.

Além das limitações farmacotécnicas descritas, os usuários desses produtos foram expostos a: novasindicações terapêuticas para vel hos princípios ativos sem a devida comprovação científica; associações irracionais de vários fármacos em doses fixas, antagonismo terapêutico; sonegação de informação sobre a composição e ainda erros grosseiros de manipulação, por exemplo $0^{8,9,11-15}$ Outros estudos sobre prescrição e dispensação de medicamentos psicotrópicos apontavam práticas abusivas e ilegais das farmácias e prescritores de fórmulas magistrais ${ }^{14,15}$.

A problemática dos M M s se agrava quando a Anvisa constata, ainda, que a aplicação integral do regulamento sobre manipulação em vigor desde o ano 2000 (Resolução RDC 33/2000 da Anvisa) "levaria à interdição da maioria dos estabelecimentos ${ }^{\prime \prime}$ (destaque nosso). Justificando a entrada em consulta pública deum novo regulamento para M M, talvez por inação do referido, acrescenta: A nova proposta define categorias de diferentes complexidades, que permitem às pequenas farmácias continuar no negócio, desde que restrinjam sua atuação a produtos de menor risco6.

Cabe refletir, por fim, sobre os motivos pelos quais esses estabelecimentos prosseguiram em flagrante descumprimento da legislação então vigente, considerando que as farmácias de manipulação não são serviços essenciais ao Sistema Único deSaúde(SUS) equea descontinuidadede seu funcionamento não traz transtornos à assistência farmacêutica da população brasileira ${ }^{12}$.

Em 2007, a Anvisa publicou as novas regras para as farmácias magistrais. Nenhuma restrição foi feita à manipulação de qualquer fármaco, inclusive aos altamente potentes ${ }^{16}$. Resta saber da capacidade operacional instalada no Sistema Nacional de Vigilância Sanitária (SNVS) para "administração coletiva das externalidades potenciais negativas" advindas do novo regulamento dos M M. Segundo Lucchese, externalidades são efeitos externos negativos que podem se propagar, materializando o risco sanitário ${ }^{3}$.

A problemática dos M M s traz à tona a discussão sobre a organização do SNVS, principalmente no que se refere a sua estrutura para fazer cumprir o novo ordenamento, exigindo aumento da sua capacidade fiscalizadora, já com sérias limitações. Os problemas crônicos deinfraestrutura dos componentes do sistema, principalmente os estaduais e municipais, como recursos hu- manos, suporte laboratorial, sistema de informação etc., são reconhecidos ${ }^{2,3}$. 0 componente laboratorial é considerado como um dos mais críticos do SNVS, ainda que de fundamental importância para a finalização das ações de caráter fiscalizador da Visa2-5. Essa importância se deve à Lei $n=6.437 / 77$, que instrui o processo administrativo dos produtos sujeitos à $V$ isa e remete a apuração de agravos à saúde à apreensão de amostras para avaliação laboratorial ${ }^{2}$. A legislação sanitária também determina os critérios, descritos nas farmacopeias, que o LVS deve utilizar para avaliar a qualidade mínima ${ }^{2,17}$. A questão em pauta é que ela não contempla as peculiaridades dos MMs.

Já a Portaria no 2.031/GM /2004 ${ }^{18}$ estabelece que as unidades integrantes da Rede $\mathrm{N}$ acional de Laboratórios de Visa (LVS) devem realizar análises vinculadas às funções do SNVS em produtos de interesse à saúde. Compõem essa rede 27 Laboratórios Centrais de Saúde Pública (Lacen) - um em cada estado eum no Distrito Federal. E no nível federal, embora não referido na portaria, o Instituto Nacional de Controle de Qualidade em Saúde (INCQS/Fiocruz), único criado com esta finalidade.

A grandemaioria dos Lacens incluiu recentemente al guns produtos de interesse da Visa (alimentos, basicamente) entre suas funções e tem pouca cultura institucional com a realização das análises previstas na legislação sanitária. Alguns estudos apontam para falta de entrosamento com as Visas locais, falta de padrões, de métodos analíticos, de equipamentos e de pessoal capacitado, principal mente nos ditames da legislação específica dos produtos ${ }^{2,3,19}$. 0 processo de cooptação dos LVS, assim como a constituição dessa rede, ainda não foram objeto de estudo. É nesse contexto que este trabal ho se insere: discutir os desafios para a rede de Laboratórios de Vigilância Sanitária (LVS), focalizando a problemática dos medicamentos manipulados (M M) como estudo de caso.

A partir dos resultados da pesquisa "Situação dos medicamentos manipulados (M M s) nos laboratórios de vigilância sanitária (LVS)"13, realizada pelo Centro Colaborador deV igilância Sanitária da Escola N acional de Saúde Pública Sergio Arouca (Cecovisa/Ensp) efinanciada pelo convênio com a Anvisa, finalizada em 2006, apresentam-se e problematizam-se elementos que possam contribuir para a reflexão sobre a estruturação do SN V S no enfrentamento de apreensões de amostras previstas na legislação sanitária, usando o M M como organizador da discussão. 


\section{I dentificação do laboratório}

Foram identificados oito LVS que analisavam regulamente medicamentos no país em $2005^{19,20}$. Aos diretores dos oito laboratórios foram encaminhadas cartas de apresentação do projeto e convite para a participação, assim como um questionário sucinto sobreinformações gerais daárea de análise de medicamentos no LVS. Tais informações estavam indisponíveis no levantamento bibliográfico.

\section{Seleção das amostras}

O levantamento dos M M s teve como fonte de dados secundários o Sistema de Gerenciamento deAmostras (SGA), criado em 1999 pelo INCQS/ Fiocruz e implantado em alguns LVS. Trata-se de um banco de dados sobre produtos analisadosno país. A seleção contou com um programa específico elaborado pelo setor de informática do INCQS, abarcando o período de janeiro de 2000 a setembro de 2005, e as variáveis de interesse ao estudo, selecionadas a partir dos campos do SGA: (1) Requerente (demandante) da análise; (2) Modalidade de análise; (3) Motivo da apreensão (solicitação); (4) Situação final das amostras; (5) Avaliação (resultado, conclusão, laudo) final; e (6) Ensaios efetuados.

A pós o processamento dos dados dos M M S enviados pelos LVS, capturados nos respectivos SGAs, identificaram-se lacunas equestionamentos sobre as amostras e/ou a conclusão analítica. Selecionaram-seostrês laboratórios mais expressivos para visita e elucidação das dúvidas, recorrendo-se aos respectivos processos (fonte primária) que, a princípio, os laboratórios deveriam constituir. Priorizaram-se as amostras que envolviam questionamentos sobre a segurança e/ou eficácia do M M , configurando-os como um Problema de Saúde Pública a Ser Investigado (PSPI). As variáveis aqui apresentadas são resultantes do cruzamento desses dados do SGA com os documentos retidos nos LVS.

\section{M étodo}

Trata-se de discussão qualitativa sobre dados das amostras de M M s e levantadas no período nos LVS identificados. As "variáveis" selecionadas para discussão são inerentes ao processo de trabalho interno aos LVS, reproduzindo o fluxo da chegada da amostra, materializando-a como um PSPI e demandada por agentes externos aos la- boratórios e envolvidos na apuração de agravos à saúde de M M s, até a elucidação do PSPI, corporificada no laudo. Assim, os três conjuntos de situações a serem trabalhados são:

I- O LVS como instituição em construção: apresentam-se e discutem-se as informações coIhidas em questionário elementar sobre a constituição da área analítica no LVS.

II- Interfaces do componente laboratorial: apresentam-se os LVS e problematiza-se como eles significam e processam os PSPIs a partir das variáveis "requerente das análises", os demandantes, e quais foram os critérios de enquadramento na "modalidade de análise".

III- A avaliação laboratorial: três variáveis foram escolhidas para discussão da emissão do laudo: (1) situação final - o interesse é aproximar-se dos cancelamentos de amostras e levantar seus motivos; (2) avaliação final - que materializa a resposta do LVS aos demandantes; (3) ensaios realizados - que problematizarão o resultado, dialogando com os motivos da demanda e a pertinência e suficiência da eleição dos ensaios realizados para a elucidação da fontedeagravo (PSPI).

\section{Resultadosediscussão}

\section{O LVS como instituição em construção}

A pesquisa transversal retrospectiva realizada nos LVS envolvidos na avaliação de medicamentos no período de 2000 a 2005 possibilitou identificar e perscrutar alguns dos laboratórios do país que lidam com avaliação desse produto - em especial, que analisaram M Ms.

Em 2005, os oito LVS contatados tinham mais de vinte anos de existência. Q uatro analisavam regularmente medicamentos há pelo menos 15 anos, e o restante, entre cinco e nove anos. Um não avaliou M M s, e os restantes os haviam analisado nos últimos cinco anos. Esse sucinto levantamento reivindica al gumas reflexões.

A maioria dos Lacens atua há mais de cinquenta anos na área das análises clínicas e bromatológicas, vinculadas basicamenteà vigilância epidemiológica. No entanto, a atuação laboratorial em Visa de medicamentos só foi incorporada recentementeàs ações regulares de suas práticas institucionais. As apreensões esporádicas de medicamentos, resultantes da ausência de políticas e serviços de fiscalização estruturados, tampouco corroboraram a estruturação do setor e o acúmulo de expertise nos Lacen $5^{2,3}$.

Segundo o último relatório sobre os Laboratórios Oficiais da Anvisa ${ }^{19}$, 12 dentre 28 LVS ana- 
lisaram medicamentos em 2004. Entretanto, sem explicitar os critérios, apenas um é apontado como estruturado para realizar a totalidade dos ensaios preconizados para esse produto. A questão da expertise institucional em analisar determinados produtos de interesse à $V$ isa vem sendo pouco valorizada na discussão da estruturação do sistema e de programas específicos. Caso essa premissa esteja equivocada, como justificar a ausência desse dado na literatura, nos sucessivos relatórios de avaliação da Anvisa ${ }^{19,21}$ e nos critérios de participação nos programas de verificação da qualidade de medicamentos (Proveme) propostos pela Anvisa ${ }^{20}$ ? A indústria, em geral, considera cinco anos de experiência como tempo suficiente para formação deexpertise. Qual o tempo institucional eindividual para adquirir expertise em campos tão complexos como medicamentos, com legislações e metodologias analíticas nem sempre disponíveis ou insuficientes ${ }^{3,17}$ ? E o monitoramento da qualidade, na perspectiva da Visa, éuma área constituída einstruída no Brasil? E a cultura institucional do LVS reflete sobre essas questões? Se essas e outras questões não são colocadas como critério de avaliação e acompanhamento, como conhecêlas?

Outras informações levantadas no questionário encaminhado aos oito LVS foram o quantitativo e a jornada de trabal ho dos analistas de medicamentos. Os números declarados variaram de dois a 23 por laboratório, totalizando 71 técnicos nos oito LVS, dos quais apenas $38(53 \%)$ tinham dedicação exclusiva ( $8 \mathrm{~h} / \mathrm{dia}$ ); 87\% desses profissionais estavam concentrados em apenas dois laboratórios. A disponibilidade de analista foi crítica em três laboratórios, considerando que a quase totalidade dos técnicos tinha vínculo de apenas vinte horas semanais.

0 último relatório da Anvisa ${ }^{21}$, um aglome rado de dados agregados de difícil identificação de informações que propiciem uma discussão mais substanciada sobre os recursos humanos envolvidos com cada área de atuação, informa a existência de 1.539 trabalhadores nos 25 LVS (três Lacens não participaram), distribuídos em 14 áreas de atuação; que a distribuição da jornada de trabal ho de 30 e 40 horas semanais é de $42 \%$ e $38 \%$ dos recursos humanos disponíveis, respectivamente; que $56 \%$ possuem formação universitária, dos quais $16 \%$ com mestrado e $4 \%$ com doutorado. Toda a ênfase do levantamento e discussão é o número de amostras analisadas, sem entrar no mérito das complexidades analíticas dessas amostras segundo o programa, entre outras. I guala análise deágua de consumo humano com medicamentos, hemoderivados, artigo de saúde etc., assim como a realização de uma medição de pH com uma de espectrometria de absorção atômica acoplada com forno de grafite (EAA/FG) ou gerador de hidretos (EAA/GH).

$E$ aqui não sepodeesquivar às perguntas: considerando os ensaios imprescindíveis, quantos analistas/hora são minimamente necessários à estruturação da área de medicamentos no LVS?E para viabilizar a realização de todos os testes previstos em farmacopeias ${ }^{2}$ ou no Provem $e^{20} \mathrm{em}$ monitoramento de rotina? Qual éa infraestrutura mínima e necessária para o LVS ser considerado como habilitado para analisar medicamento em monitoramento programado? Qual deva ser o desenho da rede, considerando quenem tudo é rotina? Quanto a denúncias graves, os PSPIs apurados pela fiscalização necessitarão de abordagens analíticas difer enciadas enem sempredisponíveis nas farmacopeias ${ }^{17}$ ? N enhuma farmacopeia é perene, e são justamente os PSPIs que provocam suas revisões 2 . Como estruturar a rede para captar "informações imperfeitas e insuficientes" 3 sobre sistemas de avaliação de medicamentos no Brasil? Essas questões e outras, como por exemplo conceitos impróprios ("desvios dequalidade" da indústria usados para amenizar os PSPIs), merecem reflexão profunda por partedo SNVS, pois atingem 0 âmago da função analítica inteligente dos LVS, que deve ir muito mais além do que aprovar ou reprovar lotes de medicamentos.

A última informação solicitada no questionário deste estudo foi sobre o quantitativo do pessoal envolvido com análise de M M. Do total dos 71 analistas de medicamentos disponíveis nos LVS, 45 (63\%) foram declarados também como executores das análises de M M. Em três laboratórios, representaram $100 \%$ dos técnicos disponíveis. A diferença significativa entre os disponíveis e os executores se deu nas três instituições com maior disponibilidade de pessoal.

0 intuito dessa questão era vislumbrar se já havia algum tipo de divisão interna de trabalho nos LVS segundo complexidade do produto ou do agravo à saúde. $\mathrm{E}$ a problemática do $\mathrm{M} \mathrm{M}$ vem-se mostrando paradigmática nessa direção, considerando três premissas: a primeira éintrínseca à natureza do trabalho laboratorial, que, ao executar, destrói a prova. E no M M essa questão écrítica, devido ao número pequeno deunidades disponíveis, acarretando inclusivefrequentescancelamentos ou laudos inconclusos, conformediscutido adiante. A segunda reside na complexidade desse tipo de demanda analítica, que relata fatos (intoxicações, internações, comas, mortes) muitas vezes indevidamente apurados, exigindo um profundo conhecimento farmacotécnico ca- 
paz de associar o PSPI aos possíveis ensaios que possam identificá-lo. A terceira é de natureza operativa e intrínseca à atividade de vigilância sanitária: não existe monografia oficial ou método de análise preestabelecido para a fiscalização laboratorial de M M. Significa dizer que o diagnóstico do PSPI dependerá exclusivamente da experiência e da capacidade perquiridora do especialista em identificar problemas graves em medicamentos.

Apesar de se tratar de um questionário ele mentar e não estruturado, as questões aqui levantadas precisam ser mais bem estudadas ediscutidas, sobretudo quando se reivindica aos LVS estruturação adequada ao exercício de inteligência perquiridora, buscando efetividade no diagnóstico de possíveis fontes de agravos, assim como a conformação de um Sistema Nacional de Laboratórios de Saúde Pública hierarquizado por grau de complexidade, prevista na Portaria $n^{0} 2.031 / 04^{18}$.

\section{0 processamento das amostras}

Dos oito LVS envolvidos no projeto, apenas dois não enviaram as informações referentes às amostras: um por não ter analisado M M s no período estudado; e o outro, alegando que o resgate no SGA estava comprometido, já que não houve discriminação entre medicamentos manipulados e industrializados na hora de alimentar 0 banco.

Embora o SGA tenha sido objeto de estudo no projeto ${ }^{13}$ que gerou este trabal ho, não se pretende aqui discutir os problemas verificados na implementação ealimentação do único banco de dados de amostra analisadas no país e de interesse do SNVS. Registra-se que foi verificada a falta de harmonização na alimentação do SGA. Esse diagnóstico só foi possível quando do cruzamento dos dados das planilhas do SGA, enviadas pelos LVS, com as informações dos processos das amostras de dois laboratórios visitados. O terceiro LVS, na ocasião, não tinha a prática institucional de formar processos para amostras demandadas, inclusive as dos órgãos de fiscalização da Visa. 0 resgate das informações nesse LVS foi possível devido ao hábito dos analistas de reter os principais documentos e pelo fato de a maioria das amostras ter entrado nos últimos dois anos do levantamento. Os fatos descritos só corroboram a premissa de o LVS ser ainda uma instituição em construção.

A questão da formação do processo da amostra deve ser discutida pelo SNVS. Onde existe, facilita 0 acesso do analista a toda a documenta- ção referente à demanda, como ofício com discrição da denúncia eda investigação efetuada pelo órgão demandante, Termo de Apreensão (ou Coleta) de Amostra (TAA, TCA), rótulos, bulas, assim como registro de todas as medidas tomadas pelo laboratório, por exemplo. Esses documentos são memórias dos PSPIs. $\mathrm{Na}$ era da informática, o que fazer com essa documentação que funda a ação dos LVS como investigação de agravo à saúde?

A falta de uniformidade na alimentação do SGA inviabilizou a discussão conjunta das 376 amostras que entraram nos seis laboratórios no período. A seguir, apresentam-se as questões consideradas relevantes nas 347 amostras processadas nos três LVS visitados.

Interfaces do componente laboratorial

Não é função do LVS coletar amostra, salvo para pesquisas específicas. Como instituição pública, esses laboratórios vêm-se configurando como espaço de articulação intersetorial, captando os principais problemas no uso de produtos de interesse da $V$ isa eidentificando os segmentos envolvidos na investigação de agravosà saúde dos usuários de M M s. Assim, a Tabela 1 informa que $74 \%$ das amostras foram recolhidas pelos órgãos de Visa das três esferas de governo, inclusive de Lacens; $20 \%$ delas foram originadas nos órgãos vinculados ao Poder Judiciário, M inistério Público e Delegacias de Defesa do Consumidor. Outros $6 \%$ dessas amostras, embora encaminhadas por Lacens, Anvisa e Visas estaduais, foram solicitadas pelo Senado, como demanda da CPI dos M edicamentos, e por proprietários de patentes de medicamentos denunciando farmácias de manipulação que faziam uso do nome comercial, outra ilegalidade dessas farmácias.

Constatou-se que $45 \%$ das amostras de M M s passaram antes por 15 Lacens que, por algum motivo, se consi deraram inabilitados para a realização da avaliação, encaminhando-as a dois dos LVS da pesquisa. Essa situação já foi objeto de indagação no último relatório da Anvisa ${ }^{19}$ e precisa ser discutida pelo SNVS.

Esperava-se que o "demandante" fosse a primeira variável a organizar o processo de trabaIho interno nos LVS, identificando as "externalidades potenciais negativas" ${ }^{3}$ dos PSPIs e direcionando a modalidade de análise, assim como a abordagem analítica. Essa premissa fica esvaziada quando se verifica que dos $74 \%$ provenientes dos órgãos de Visa apenas 33\% foram enquadrados com análise fiscal e observaram os ditames legai $5^{22,23}$, embora em pelo menos $70 \%$ desse 


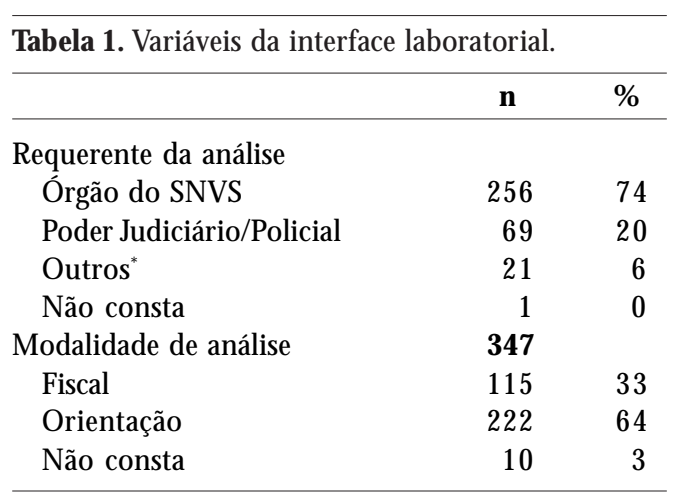

*Outros: amostras demandadas pelo Senado como auto da CPI demedicamentose por donos de patente/marcas.

universo constasse o TAA ou semelhante. OsLVS têm alterado o ritual do processo administrati$\mathrm{vo}^{23}$ queenvolveapreensão de amostras de M M s, transformando análisefiscal em modalidadenão prevista em lei ${ }^{22}$. Tudo indica que a anomia exercida pelo LVS encontra espaço no SNVS, uma vez que nenhum questionamento é feito nessa direção. Alguns analistas justificaram esse procedimento devido à natureza dos $\mathrm{MM} \mathrm{s}$, por se tratar de amostras únicas, abertas e geralmente em quantidades insuficientes para as análises previstas, o que é fato. Não deveriam provocar 0 SNVS para se posicionar sobre a problemática?

Já as amostras do Poder Judiciário/policial (20\%) assumem outros objetivos e implicações mais próximas da ótica dos institutos médicoslegais, explicitando a "externalidade" perigosa dos M M s. Resta perscrutar: os LVS estão fazendo convênios e se apropriando de técnicas que propiciem esse tipo de avaliação, já que se acredita que seus analistas não acumulam expertise para investigações de natureza criminal, podendo incorrer inclusiveem ilegalidades? A mesmalógicaderaciocínio se aplica às "outras" amostras, algumas assumindo defesa de propriedade intelectual.

Tinha-se muita pretensão com o levantamento dos "motivos da solicitação" de análise, variável que melhor viabiliza a discussão da interface entre os demandantes e o componente laboratorial. Ela demonstraria, por um lado, como os demandantes investigam a fonte de agravo e, por outro, como deveria se agregar direcionamento à abordagem analítica. Essa informação não está disponível em pelo menos $25 \%$ das amostras da Visa. E, quando existe, não vem sendo alimentada no SGA. Ademais, os TAAs, quando mencionam, relatam situações genéricas, denotan do falta de apuração da fiscalização da Visa. A discussão profícua das questões levantadas nessa variável necessitaria de mais espaço para apresentação.
No entanto, a maioria das amostras provenientes do Judiciário vem mais bem documentada.

\section{A avaliação laboratorial dos M M s no LVS}

O levantamento da variável "situação final" informa que, do total de 347 amostras, 239 (69\%) foram analisadas, $89(26 \%)$ canceladas e 19 (5\%) sem conclusão. Essa informação praticamente não consta no SGA enem sempre está registrada no processo. Verificou-se caso de amostras que sequer foram cadastradas no SGA, e outro de duplo cancelamento da mesma amostra (passou em dois LVS). Os principais motivos para o cancelamento, coletados nas visitas, foram: falta de substância química de referência; falta demetodologia; prazo de validade vencido; e amostras insuficientes, sem documentação etc.

Ao se levantar a variável "motivo da apreensão" das amostras canceladas, verifica-se que em $36 \%$ desse universo não constava documentação que atribuísse plausibilidade à realização da análise, denotando a fragilidade dos órgãos de Visa.

Questiona-se a subjetividade da decisão de cancelamento quando se verifica que uma das justificativas mais citadas é a falta de metodologia - e, a princípio, inexiste metodologia oficial para a maioria das associações medicamentosas praticadas no M M , o que ocasionaria um cancelamento muito maior do que 0 averiguado.

Até amostras programadas no Proveme ${ }^{20}$ foram canceladas "por motivos técnicos", evidenciando a urgência em prover meios aos LVS que os habilitem a atuar nos PSPI.

0 resultado do laudo

$\mathrm{Na}$ Tabela 2 verifica-se que, das 239 amostras que tiveram conclusão final, 190 (79\%) foram insatisfatórias (reprovadas?) e 49 (21\%) consideradas satisfatórias (aprovadas?). Essas designações, mais uma vez, não atendem à Lei $n=6.360 /$ $67^{22}$, queestabeleceno art. 62 as designações para medicamentos como: "alterado, adulterado ou impróprio para o uso", definindo cada uma dessas situações.

Nesse sentido, ao cruzar os ensaios realizados com os motivos da demanda da análise, conclui-se que, das 49 amostras que tiveram laudo conclusivo como "satisfatório", em pelo menos $20(40 \%)$ a abordagem analítica não propiciou a eleição de ensaios mais adequados para responder aos motivos de sua demanda. $\mathrm{Na}$ mesma direção, os laudos "insatisfatórios" deixaram de averiguar as reais fontes de dano à saúde em pelo menos 44 (23\%) dessas amostras. Os critérios 
utilizados nessa avaliação estão exemplificados nos quadros 1 e 2, respectivamente, assim como a indicação dos exames não realizados e considerados mais apropriados à avaliação.

No M M , ao se receber um laudo com a classificação de "satisfatórios" quando sequer houve ensaios imprescindíveis para tangenciar as possíveis causas do PSPI, deveria constar uma observção alertando para os ensaios não realizados e, se possível, as justificativas para a não execução.

Um produto sob suspeita de associação a mortes ou internações receber um laudo que o classifica como "insatisfatório" apenas pelo rótulo e/ou por parecer técnico é algo sobre o qual

Tabela 2. Conclusão dos laudos e discussão da abordagem analítica.

\begin{tabular}{lrrrrrr}
\hline \multicolumn{3}{c}{$\begin{array}{c}\text { Resultado final das } \\
239 \text { amostras de M M }\end{array}$} & & & \multicolumn{3}{c}{$\begin{array}{c}\text { Abordagem não } \\
\text { respondeu à denúncia }\end{array}$} \\
\hline Conclusão & $\mathrm{n}$ & $\%$ & & $\mathrm{n}$ & $\%$ \\
\hline Satisfatória & 49 & 21 & & 20 & 40 \\
Insatisfatória & 190 & 79 & & 44 & 23 \\
\hline
\end{tabular}

- SNVS deveria refletir. Da mesma forma que o LVS emitiu o laudo, os demandantes tampouco analisaram os resultados e suas implicações para depuração dos motivos da solicitação do PSPI .

Sem espaço para detalhamentos, registra-se que todos os ensaios previstos na farmacopeia brasileira são para produtos industrializados e que nem sempre é viável realizá-los nos M M s, pois requerem número de unidades nem sempre disponível, embora vital para imputar alguma segurança e/ou eficácia do produto. 0 ensaio de uniformidade de doses unitáriaséum dosfatores imprescindíveis para essa finalidade, principalmente para fármacos potentes. 0 ensaio de teor é outro que deve ser revisto: juntar o conteúdo de dez cápsulas com distintas concentrações, homogeneizar edepois medir éimputar uma qualidade terapêutica que o M M não possuía. O LVS precisa refletir sobre essas questões e investir na constituição degrupos deinteligência capazes dedirecionar a avaliação para o diagnóstico das reais fontes de agravos dos M Ms. E até não emitir o laudo, caso seja inviável a avaliação adequada.

Quadro 1. Casos de amostras de M M com laudo final "satisfatório", consideradas com abordagem analítica insuficiente para responder aos motivos da demanda.

\begin{tabular}{|l|l|l|l|}
\hline \multicolumn{1}{|c|}{ Produto } & Motivo da demanda & \multicolumn{1}{|c|}{$\begin{array}{c}\text { Abordagem analítica } \\
\text { realizada }\end{array}$} & $\begin{array}{l}\text { Ensaios não realizados } \\
\text { no princípio ativo (PA) }\end{array}$ \\
\hline $\begin{array}{l}\text { Brometo Propantelin } \\
\text { (5mg), Xarope } \\
\text { Groselha 5mL } \\
\text { (solução) }\end{array}$ & $\begin{array}{l}\text { Reações psicológicas } \\
\text { (agressividade, } \\
\text { desorientação, } \\
\text { perturbação de } \\
\text { memória) }\end{array}$ & $\begin{array}{l}\text { Rotulagem; contagem de } \\
\text { bolores, leveduras ede } \\
\text { bactérias aeróbias; } \\
\text { Pesquisa de: escherichia } \\
\text { coli; salmonella sp; } \\
\text { staphylococcus aureus; } \\
\text { outros microorganismos }\end{array}$ & $\begin{array}{l}\text { Identificação e } \\
\text { doseamento do PA }\end{array}$ \\
\hline $\begin{array}{l}\text { Amitriptilina } \\
\text { (cápsula) }\end{array}$ & $\begin{array}{l}\text { Monitoramento da } \\
\text { qualidade e eficácia no } \\
\text { produto manipulado }\end{array}$ & $\begin{array}{l}\text { Rotulagem; aspecto; } \\
\text { identificação }\end{array}$ & $\begin{array}{l}\text { Ensaio de uniformidade } \\
\text { de conteúdo. "Na } \\
\text { impossibilidade", } \\
\text { doseamento unitário de } \\
\text { cápsulas }\end{array}$ \\
\hline $\begin{array}{l}\text { Thiomucase-100utr, } \\
\text { Aloína-45mg, } \\
\begin{array}{l}\text { Ranitidina-50mg, } \\
\text { H.clorotiazida-2,5mg, } \\
\text { Spirulina-200mg, } \\
\text { Clorella-80mg, } \\
\text { Clordiazepóxido-4mg } \\
\text { T3-0,09mg (cápsula) }\end{array}\end{array}$ & $\begin{array}{l}\text { Consumidor sentiu } \\
\text { tonteira e sonolência } \\
\text { após ingerir o produto }\end{array}$ & $\begin{array}{l}\text { Rotulagem; aspecto; } \\
\text { identificação de } \\
\text { clordiazepóxido }\end{array}$ & $\begin{array}{l}\text { Ensaio de uniformidade } \\
\text { de conteúdo de T3 e } \\
\text { clordiazepóxido. "Na } \\
\text { impossibilidade", } \\
\text { doseamento unitário em } \\
\text { cada cápsula }\end{array}$ \\
\hline
\end{tabular}


Quadro 2. Casos de amostras de M M , com avaliação final "insatisfatório", consideradas com abordagem analítica insuficiente para responder aos motivos da demanda.

\begin{tabular}{|l|l|l|l|}
\hline \multicolumn{1}{|c|}{ Produto } & M otivo da demanda & \multicolumn{1}{|c|}{$\begin{array}{c}\text { Abordagem analítica } \\
\text { realizada }\end{array}$} & $\begin{array}{l}\text { Ensaios não realizados } \\
\text { no princípio ativo (PA) }\end{array}$ \\
\hline $\begin{array}{l}\text { Prednisona/ } \\
\text { paracetamol/ } \\
\text { ibuprofeno }\end{array}$ & $\begin{array}{l}\text { Suspeita de dosagem } \\
\text { inadequada; internação } \\
\text { hospitalar; síndrome de } \\
\text { Cushing }\end{array}$ & $\begin{array}{l}\text { Rotulagem: } \\
\text { insatisfatória;parecer } \\
\text { técnico: a dose diária de } \\
\text { prednisona é de três vezes } \\
\text { maior que a máxima } \\
\text { recomendada; quadro } \\
\text { clínico compatível com a a } \\
\text { superdosagem de } \\
\text { prednisona }\end{array}$ & $\begin{array}{l}\text { Identificação e dosagem } \\
\text { de prednisona }\end{array}$ \\
\hline $\begin{array}{l}\text { Composto } \\
\text { emagrecedor }\end{array}$ & $\begin{array}{l}\text { O produto causa: } \\
\text { taquicardia, secura na } \\
\text { doca, náuseas e mal- } \\
\text { estar geral }\end{array}$ & $\begin{array}{l}\text { Rotulagem: } \\
\text { insatisfatório;peso médio: } \\
\text { insatisfatório }\end{array}$ & $\begin{array}{l}\text { Pesquisa de anfetaminas e } \\
\text { benzodiazepínicos }\end{array}$ \\
\hline $\begin{array}{l}\text { Hormônio do } \\
\text { crescimento humano }\end{array}$ & $\begin{array}{l}\text { óbito de um paciente e } \\
\text { internação de outro }\end{array}$ & $\begin{array}{l}\text { Rotulagem: } \\
\text { insatisfatório,identificação: } \\
\text { satisfatório }\end{array}$ & $\begin{array}{l}\text { Ensaio de uniformidade } \\
\text { de conteúdo. "Na } \\
\text { impossibilidade", } \\
\text { doseamento unitário das } \\
\text { cápsulas }\end{array}$ \\
\hline
\end{tabular}

\section{Consideraçõesfinais}

Asreflexões realizadas nestetrabalho tiveram como fonteinspiradora a problemática dos medicamentos manipulados a partir das amostras captadas nos LVS. 0 estudo permitiu identificar questões que extrapolam as fronteiras dos laboratórios, denotando que a capacidade investigativa deve ser mais bem apropriada pelos entes do SN VS. O componente laboratorial, como elemento do sistema, ao captar as informações imperfeitas e insuficientes, deve interagir com os outros componentes no sentido de aprimorar a capacidade nacional em diagnosticar fontes de agravos à saúde da população. Inclusive apontar todo e qualquer limitante que inviabiliza sua atuação como laboratório capaz de analisar "problemas de saúde pública a serem investigados", materializados nessas amostras.

Outra prática que os LVS devem instituir em sua cultura institucional é a avaliação da abordagem analítica quanto a sua capacidade de responder aos PSPI.

Cabeà Política Nacional deVigilância Sanitária de medicamentos assegurar uma oferta terapêutica nacional de qualidade, respeitando os atributos de segurança ea eficácia dos medicamentos disponíveis no país. Desse ponto de vista, não há justificativa para seflexibilizarem as exigências de qualidade em relação à oferta de subconjuntos como os medicamentos manipulados.

Antes de permitir flexibilizações regulatórias, deve-seavaliar a capacidade do SNVS em lidar com o objeto a ser monitorado, inclusive providenciar os meios imprescindíveis à função laboratorial.

\section{Colaboradores}

ACP Silva foi responsável pela concepção, condução, análise dos dados, estruturação do artigo e redação do texto; CVS O liveira foi responsável pelo levantamento e tabulação dos dados, análise da pesquisa e estruturação dos dados do artigo; M VSCavalheiro e M CC M iranda foram responsáveis pelo levantamento dos dados e análise da pesquisa. 
Referências

1. Rozenfeld S. Farmacovigilância: elementos para a discussão e perspectivas. Cad Saude Publica 1998; 14(2):237-263.

2. Silva ACP. 0 laboratório oficial na avaliação analítica. In: Rozenfeld S, organizador. Fundamentos da vigilância sanitária. Rio de Janeiro: Editora Fiocruz; 2000. p. 271-301.

3. Lucchese G. Globalização e regulação sanitária: os rumos da vigilância sanitária no Brasil [tese]. Rio de Janeiro: Ensp/Fiocruz; 2001.

4. Novaes HMD, Carvalheiro JR. Ciência, tecnologia e inovação em saúde e desenvolvimento social e qualidade de vida: teses para debate. Cien Saude Coletiva 2007; 12(Supl.):1841-1849.

5. Silva $A C P$, Pepe VLE. Vigilância sanitária: campo da promoção e proteção. In: Giovanella L, Escorel S, Lobato LVC, Noronha JC, Carvalho Al, organizadores. Políticas e sistema de saúde no Brasil. Rio de Janeiro: Editora Fiocruz; 2008. p. 819-849.

6. Brasil. Ministério da Saúde. Agência Nacional de Vigilância Sanitária. Subsídios à discussão sobre a proposta de regulamentação para farmácias magistrais. Rev Saude Publica 2005; 39(4):691-694.

7. Paumgartten FJR. Riscos de preparações manipuladas em farmácias magistrais. Boletim Sobravime 2001-2004; 38/39:22-23.

8. Misuta NM, Soares DA, Oliveira M LF. Quebra de normas de segurança na formulação de medicamentos e mortes por intoxicação pela colchicina em adultos. Rev Ciênc M éd 2006; 15(4):347-351.

9. Silva ACP, Cavalheiro MVS, Oliveira CVS. Medicamentos manipulados: uma opção de risco. In: Anais do VII Congresso Brasileiro de Saúde Coletiva. Brasília; 2003. [CD-ROM].

10. Brasil. M inistério da Saúde. Agência Nacional de Vigilância Sanitária. $0 \times$ da manipulação: regras para farmácias magistrais acendem discussão sobre segurança dos medicamentos. Boletim Informativo da Anvisa 2005; 56:6-8.

11. Cavalheiro MVS, Oliveira CVS, Ladeira EM, Silva ACP. Perfil da demanda e principais problemas dos medicamentos manipulados analisados no INCQS. Rev Bras Epidemio 2002; (Supl. Especial):102.

12. Brasil. Ministério da Saúde. Fundação O swaldo Cruz. Posição da Escola Nacional de Saúde Pública (Ensp/Fiocruz), do Instituto Nacional de Controle de Qualidade em Saúde (INCQS/Fiocruz), da Escola Politécnica de Saúde Joaquim Venâncio (EPSJV/ Fiocruz) e da Fundação Oswaldo Cruz (Fiocruz) em relação à Consulta Pública da Anvisa no 31/2005, sobre 0 Regulamento das Boas Práticas de M anipulação de M edicamentos em Farmácias. Rio de Janeiro: Fiocruz; 2005.

13. Silva ACP, Oliveira CVS, Cavalheiro MVS, Miranda MCC. Situação dos medicamentos manipulados nos laboratórios de vigilância sanitária (2000-2005) [relatório]. Rio de Janeiro: Centro Colaborador em Vigilância Sanitária da Ensp/Fiocruz; 2006.
14. Noto AR, Carlini EA, M astroianni PC, Alves VC, Galduróz JCF, Kuroiwa W, Czismar J, Costa A, Faria MA, Hidalgo SR, Assis D, Nappo SA. Analysis of prescription and dispensation of psychotropic medications in two cities in the State of São Paulo, Brazil. Rev Bras Psiquiat 2002; 24(2):68-73.

15. Andrade MF, Andrade RCG, Santos V. Prescrição de psicotrópicos: avaliação das informações contidas em receitas e notificações. Rev Bras Cienc Farm 2004; 40(4):471-479.

16. Brasil. Resolução RDC $n=67$, de 8 de outubro de 2007. Dispõe sobre boas práticas de manipulação de preparações magistrais e oficinais para uso humano em farmácias. Diário Oficial da União 2007; 9 out.

17. M iranda M CC. Reações adversas não-alérgicas à suspensão injetável de benzilpenicilina benzatina: uma revisão sistemática [dissertação] Rio de Janeiro: Ensp/Fiocruz; 2002.

18. Brasil. Portaria no 2.031, de 23 de setembro de 2004. Dispõe sobre a organização do Sistema $\mathrm{N}$ acional de Laboratórios de Saúde Pública. Diário Oficial da União 2004; 24 set.

19. Brasil. M inistério da Saúde. Agência Nacional de Vigilância Sanitária. Relatório situacional dos Laboratórios Centrais de Saúde Pública: Lacen. Brasília: Anvisa; 2006.

20. Brasil. M inistério da Saúde. Agência Nacional de Vigilância Sanitária. Relatório do Programa Nacional de Verificação da Qualidade de Medicamentos (Proveme). [site da Internet] [acessado 2006 jun 28]. Disponível em: http://www.anvisa.gov.br/inspecao/fiscalizacao/proveme/

21. Brasil. M inistério da Saúde. Agência Nacional de Vigilância Sanitária. Relatório Situacional dos Laboratórios Centrais de Saúde Pública: Lacen. Brasília: Anvisa; 2004.

22. Brasil. Lei no 6.360, de 23 de setembro de 1976. Dispõe sobre a vigilância sanitária a que ficam sujeitos os medicamentos, as drogas, os insumos farmacêuticos e correlatos, cosméticos, saneantes e outros produtos, e dá outras providências. Diário O ficial da União 1976; 24 set.

23. Brasil. Lei $n=6.437$, de 20 de agosto de 1977. Configura infrações à legislação sanitária federal, estabelece as sanções respectivas, e dá outras providências. Diário Oficial da União 1977; 24 ago.

Artigo apresentado em 09/11/2009

Aprovado em 16/06/2010

Versão final apresentada em 11/08/2010 